\title{
Human endogenous retroviruses in cancer: Expression, regulation and function (Review)
}

YUAN GAO, XIAO-FANG YU and TING CHEN

\author{
Cancer Institute, Key Laboratory of Cancer Prevention and Intervention, Ministry of Education, \\ Second Affiliated Hospital of Zhejiang University School of Medicine, Hangzhou, Zheijang 310009, P.R. China
}

Received August 12, 2020; Accepted November 27, 2020

DOI: $10.3892 / \mathrm{ol} .2020 .12382$

\begin{abstract}
Human endogenous retroviruses (HERVs) are the remnants of ancient retroviruses that infected human germline cells and became integrated into the human genome millions of years ago. Although most of these sequences are incomplete and silent, several potential pathological roles of HERVs have been observed in numerous diseases, such as multiple sclerosis and rheumatoid arthritis, and especially cancer, including breast cancer and pancreatic carcinoma. The present review investigates the expression signatures and complex regulatory mechanisms of HERVs in cancer. The long terminal repeats-driven transcriptional initiation of HERVs are regulated by transcription factors (such as Sp3) and epigenetic modifications (such as DNA methylation), and are influenced by environmental factors (such as ultraviolet radiation). In addition, this review focuses on the dual opposing effects of HERVs in cancer. HERVs can suppress cancer via immune activation; however, they can also promote cancer. HERV env gene serves a prime role in promoting carcinogenesis in certain malignant tumors, including breast cancer, pancreatic cancer, germ cell tumors, leukemia and Kaposi's sarcoma. Also, HERV ENV proteins can promote cancer via
\end{abstract}

Correspondence to: Dr Ting Chen or Professor Xiao-Fang Yu, Cancer Institute, Key Laboratory of Cancer Prevention and Intervention, Ministry of Education, Second Affiliated Hospital of Zhejiang University School of Medicine, 88 Jiefang Road, Hangzhou, Zheijang 310009, P.R. China

E-mail: tchen2013@zju.edu.cn

E-mail: xfyu1@zju.edu.cn

Abbreviations: Aza, 5-azacytidine; CSF1R, colony-stimulating factor 1 receptor; DCs, dendritic cells; DNMTi, DNA methylation inhibitor; EMT, epithelial to mesenchymal transition; HERVs, human endogenous retroviruses; HK2, HERV-K HML-2; ISU, immunosuppressive domain; KRAB-ZFP, Krüppel-associated box zinc finger proteins; KSHV, Kaposi's sarcoma-associated herpesvirus; LTRs, long terminal repeats; MITF, microphthalmia-associated transcription factor; PD-L1, programmed cell death ligand-1; PLZF, promyelocytic leukemia zinc finger

Key words: human endogenous retroviruses, env, expression regulation, cancer immunity, carcinogenesis immune suppression. Targeting ENV proteins is a potential future antitumor treatment modality.

\section{Contents}

1. Introduction

2. Expression and regulatory mechanisms of HERVs in cancer

3. Dual opposing roles of HERVs in cancer

4. Conclusion

\section{Introduction}

Human endogenous retroviruses (HERVs) are retroelements in the human genome (1). They originated from ancient retroviruses that infected our early ancestors' germ cells millions of years ago (2). According to initial sequencing and analysis of the human genome, HERV-like elements account for $\sim 8.29 \%$ of the entire Homo sapiens genome (1). Most of the HERVs are incomplete and silent due to deletions and other loss-of-function mutations; however, there are still relatively intact open reading frames in a few HERV groups, such as HERV-K HML-2, which is the most active subtype of HERV-K and will be abbreviated to HK2 hereafter (3). Complete HERVs share 4 structure genes (env, gag, pol and pro), and they are flanked by long terminal repeats (LTRs) as their regulatory elements (4). The env gene encodes envelope proteins including transmembrane and surface envelope proteins responsible for fusion and receptor recognition (5). The gag gene encodes a polyprotein that can be digested by viral proteases, which belong to the aspartic protease family, into major structural capsid and nucleocapsid proteins (6). Capsid proteins form the core of the virion and nucleocapsid proteins participate in the packaging of viral particles (7). Pol encodes reverse transcriptase and integrase proteins involved in DNA synthesis and integration into the host genome (8). Pro encodes protease involved in processing viral polypeptides, such as GAG and POL proteins (6). Concerning LTRs, these regions contain cis-acting elements and promoters that regulate gene expression (Fig. 1).

HERVs are associated with numerous diseases, including nervous system diseases (such as multiple sclerosis) $(9,10)$, infectious diseases (such as AIDS) $(11,12)$, mental disorders and 
psychiatric diseases (such as schizophrenia) $(13,14)$, obstetrical and gynecological diseases (such as preeclampsia) (15), endocrine diseases (such as diabetes) (16), dermatoses (such as lichen planus) (17,18), autoimmune diseases (such as rheumatoid arthritis) $(19,20)$ and malignant tumors. Aberrant expression of HERVs is commonly observed in cancer, encouraging researchers to investigate possible roles of HERVs. Increasing evidence has demonstrated a close relationship between HERVs and cancer. For example, data indicate that the expression of HERVs is implicated in the stage of certain cancers, such as breast cancer and hepatocellular carcinoma $(21,22)$. In addition, HERVs can activate multiple oncogenic signaling pathways (such as the Wnt/ $\beta$-catenin signaling pathway) that promote the proliferation of cancer cells and suppress their differentiation and apoptosis $(23,24)$. HERV ENV proteins have immunosuppressive properties, which also contributes to carcinogenesis (25); however, it has also been demonstrated that HERV ENV proteins can activate the immune system in cancer (26). In the present review expression signatures and regulatory mechanisms of HERVs in cancer, the effects of HERVs on carcinogenesis and their effects on cancer suppression via immune activation will be described.

\section{Expression and regulatory mechanisms of HERVs in cancer}

Expression signatures of HERVs in cancer. Compared with normal tissues, HERVs are extensively activated in diverse malignant tumors, including (27), prostate cancer (28), seminomas (29), bladder (30), ovarian (31), lung (32), hepatocellular cancer (22), leukemia (33), lymphoma (34), choriocarcinoma (35), colorectal carcinoma (36), soft tissue sarcoma (37) and Kaposi's sarcoma (38). HERV structural genes are expressed in different levels or as different variants, including full-length mRNAs (39), spliced mRNAs (34), non-coding RNAs (36), intact proteins (40) and truncated proteins (41). In cancer, activated intact proviral sequences can be transcribed into full-length mRNAs encoding intact proteins (39). RNA splicing, an important posttranscriptional regulation of gene expression, also serves a role in the expression of HERVs (34). Splice variants of $e n v$, such as rec and $n p 9$, can be translated into truncated proteins and may serve a role in carcinogenesis (41). The aforementioned point is discussed further in the section Cancer-promoting effects and mechanisms of HERVs. The efficiency of HERV mRNA splicing is associated with the orientation of transcription. For example, splicing events of HK2 mRNAs occur with sense orientation transcription, but cannot take place with an antisense orientation (42). In addition, proviral sequences can also be transcribed into non-coding RNAs through long non-coding RNA-associated transcription (39). These HERV transcripts, like transcripts of other genes in the human genome can be processed by the spliceosome and become spliced RNAs as long as they contain splice donor and receptor sites (43).

As the regulatory sequence of HERVs, HERV LTRs can also be transcribed into RNA (44). However, this type of RNA is usually transcribed by non-HERV genes, partly resulting from the random insertion of LTRs into these genes (44). Insertion of retroelements into genes may impact significant biological functions, such as cancer immunoregulation through producing new proteins (45-48). For instance, the insertion of long interspersed nuclear elements into intron 4 of the CD274 gene creates a soluble programmed death ligand-1 (PD-L1) protein, which is considered an antagonist of membrane-bound PD-L1 $(45,46)$. Analogously, the ability of a few LTR-overlapping transcripts in generating cancer-specific antigenic polypeptides has been predicted through the unique protein-coding potential prediction and immunopeptidomics analyses $(47,48)$. Studies on insertion of HERV LTRs into genes may provide a novel perspective of cancer immunotherapy (44-48). Although the identification and quantitation of these transcripts is difficult due to a plethora of LTR-overlapping transcripts, more possible roles of LTR-overlapping transcripts in cancer may be discovered in the future $(49,50)$.

Regulatory mechanisms of the expression of HERVs in cancer. HERVs expression is influenced by their regulatory sequences and regulated by transcription factors and epigenetic modifications (51-53). In addition, environmental factors may also impact the transcription of HERVs in known or unknown ways $(54,55)$.

Regulatory sequences. HERV proviral sequences are flanked by LTRs, which can act as promoters to drive the transcription of HERVs in cancer (4). The efficiency of HERVs expression is associated with the polymorphism of unique transcription factor binding sites (such as NBRE and CARF), which can be changed after integration into the human genome (51). Hence, the transcription activity of HERVs has differed in the course of human evolution due to the changing binding strength between transcription factors and their binding sites in the LTR regions $(51,56)$. In addition, the promoter sequences of LTRs are unique among the HERV groups (57-59). For example, on investigation of expression of HERV-H in colorectal tumors, a 17 bp sequence in the LTR region that was significant for the transcription of HERV-H was discovered (57). The LTRs of HERV-K exhibit a TATA-less promoter and its transcriptional initiation is mediated by $3 \mathrm{GC}$ boxes (58). For the HERV-W group in chromosome 7, a thymine at site 142 in the LTR region replaced with a cytosine drives a significant overexpression of syncytin-1 in urothelial cell carcinoma (59).

Transcription factors. Ubiquitous or specific transcription factors may regulate the expression of HERVs, such as SP1 and SP3, which are essential for the regulation of HERV-K LTRs $(58,60)$. In the teratocarcinoma GH cell line and the melanoma Mel-C9 cell line, the HERV LTR region does not contain the TATA motif or a functional initiator. Using chromatin immunoprecipitation assays, Fuchs et al (58) identified the binding of SP1 and SP3 proteins to 3 GC boxes in the LTR region. This binding acts as an initiator to activate the LTR promoter (58). With the knockdown of SP1 or SP3 using RNA interference, the LTR promoter activity reduces by $30-50 \%$ (58). In addition, the YY1 protein can modulate the activities of HERV-K LTRs (52). Although SP1, SP3, and YY1 are ubiquitous, HERV-K LTRs are not always activated in different tumor cells (53). Epigenetic modifications may partly be the reason for this (54). However, specific transcription factors may also contribute to this. For example, 


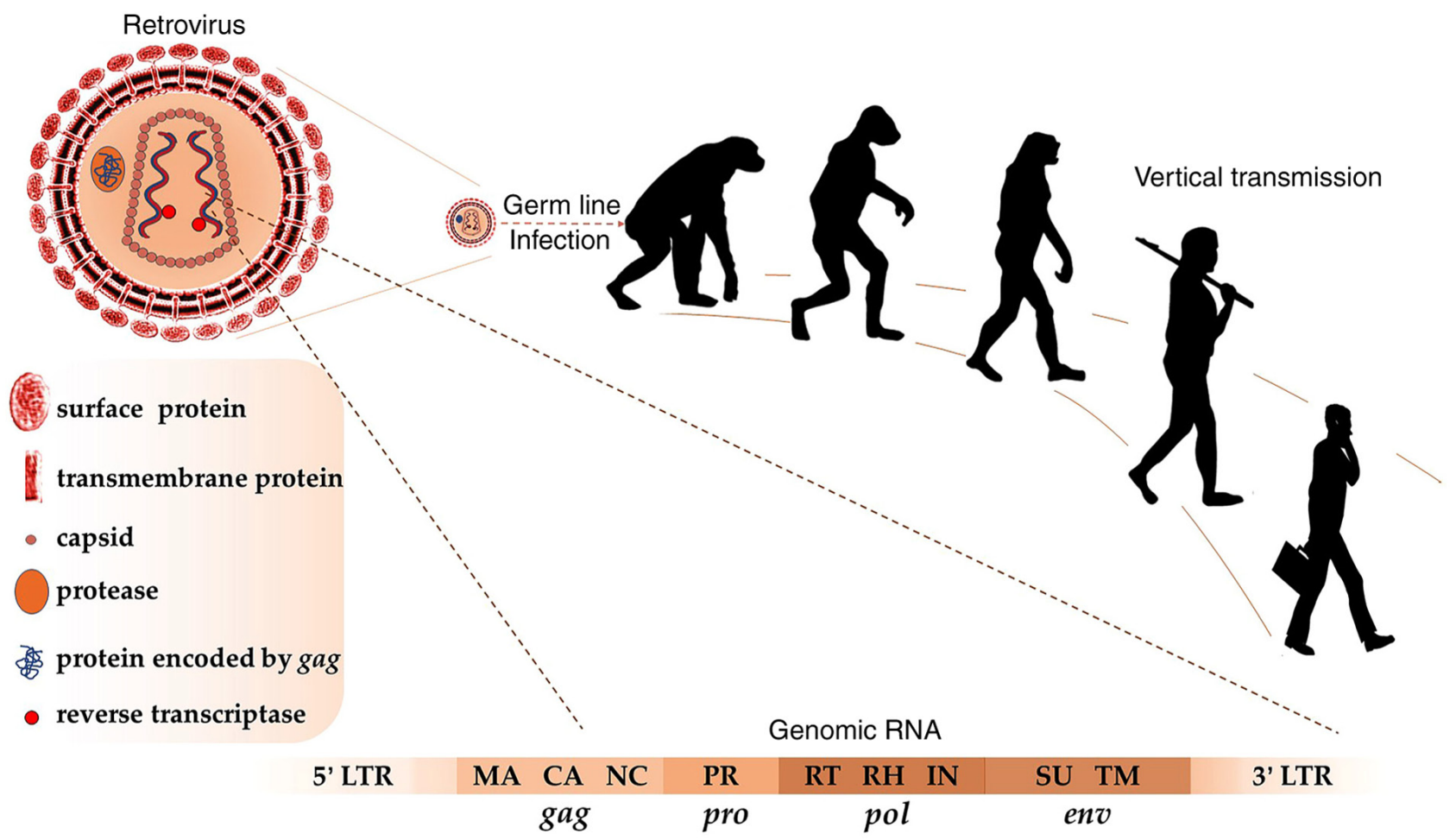

Figure 1. Retroviruses infected our early ancestors and HERVs were vertically transmitted in humans. A complete genomic HERV RNA sequence consists of gag, pro, pol and env genes, which are flanked by 5'- and 3'-LTR. MA, matrix; CA, capsid; NC, nucleocapsid; PR, protease; RT, reverse transcriptase; RH, RNase H; IN, integrase; SU, surface; TM, transmembrane; LTR, long terminal repeat; HERVs, human endogenous retroviruses.

the microphthalmia-associated transcription factor (MITF) can upregulate the expression of the HERV-K env gene in melanoma cells by interacting with a promoter composed of MITF binding motifs, 793TATA (TATA box-like sequence), and Inr 826 (transcriptional initiator site) (60). Additionally, activation of the colony-stimulating factor 1 receptor $(C S F 1 R)$ gene in Hodgkin's lymphoma, which is activated by the canonical macrophage $C S F 1 R$ promoter in healthy macrophage cells (61). NF- $\mathrm{kB}$ interacting with demethylated mammalian apparent LTR-retrotransposon LTRs replaces the canonical promoter to drive the $C S F 1 R$ gene in Hodgkin's lymphoma (61). The aforementioned information indicates that several transcription factors and epigenetic modifications may be necessary for the activation of LTRs. There may be other specific transcription factors that can modulate the transcription of HERVs with epigenetic modifications (51).

Epigenetic modifications. Epigenetic modifications are essential regulatory mechanisms for the expression of HERVs in cancer (62). The activation of HERV LTRs can be regulated by 2 major epigenetic modifications: DNA methylation and histone modifications (63). The types of epigenetic modifications can partly represent the evolutionary age of the LTRs (53). Evolutionarily young LTRs are usually $\mathrm{CpG}$-rich, and intermediate LTRs tend to be modified by histone methylation (53). Except for histone methylation, the alternative chromatin state may also regulate the transcription of HERVs via histone deacetylation modification (64).

$\mathrm{CpG}$-rich promoters tend to indicate the inactive transcription of corresponding genes (63). The DNA demethylation of HERV LTRs may contribute to the increased expression of HERVs. In the teratocarcinoma Tera-1 cell line, an association between the transcription level of HERV-K and methylation level of LTR has been observed (65). Also, the DNA hypomethylation of HERV-K and HERV-W has been discovered respectively, in urothelial carcinoma (66) and ovarian cancer (67). In particular, global hypomethylation of HERV-W has been observed in ovarian cancer (67). The aforementioned findings support the view that global hypomethylation of the genome in cancer leads to the desuppression and expression of HERVs. Such an expression of HERVs induced by hypomethylation is selective because several HERVs remain silent in cancer. For instance, 5-azacytidine (Aza) is an effective antitumor drug for hematologic tumors and also a type of DNA methylation inhibitor (DNTMi). It can upregulate some specific transcripts of HERVs in cancer, such as melanoma (68) and endometrial cancer (69). Analogously, several HERV-Ws are upregulated by Aza in neuroblastoma (70).

Histone acetylation and methylation can also impact the expression of HERVs. Histone acetylation can make local chromatin relax and genes located in the slack chromatin region are likely to be transcribed (64). On the contrary, histone deacetylation can make local chromatin tight and corresponding genes are relatively difficult to activate (64). For example, histone deacetylase inhibitors (such as Trichostatin A and Mocetinostat) exclusively induced the activity of the LTR12 promoter mediated by trimeric nuclear factor $\mathrm{Y}$ in diverse tumors (including testis cancer and lung carcinoma) (71). Notably, there may be an interplay between histone acetyltransferases and histone methyltransferases. For example, TIP60, a lysine acetyltransferase combined 


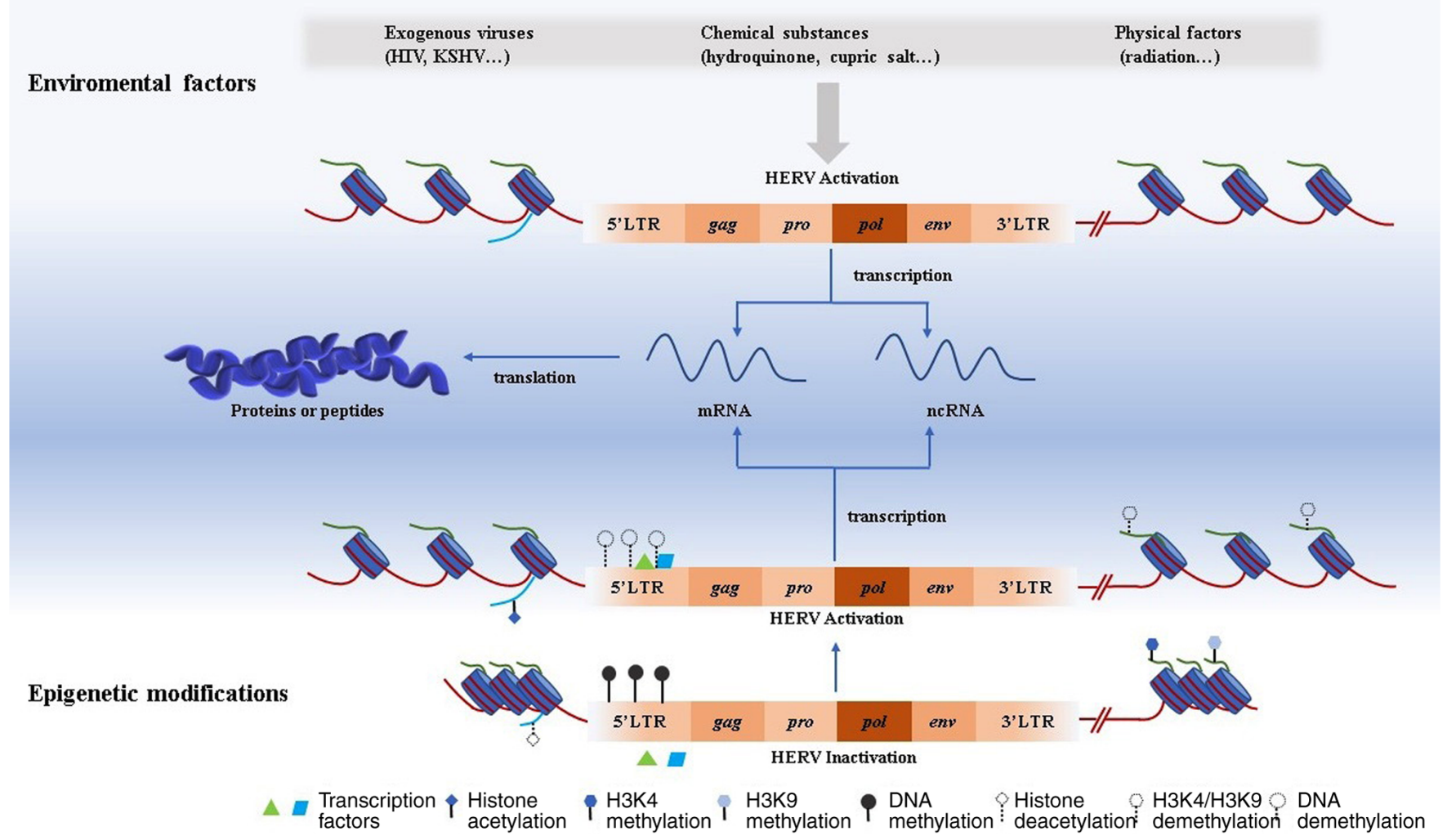

Figure 2. Activation of HERV is influenced by environmental factors and epigenetic modifications. Environmental factors including virus infection, chemical toxicity, and physical factors can impact HERV activation. Epigenetic modifications are crucial for HERV activation. DNA methylation, histone acetylation, or histone demethylation such as $\mathrm{H} 3 \mathrm{~K} 4$ and $\mathrm{H} 3 \mathrm{~K} 9$ demethylation can activate the expression of HERV. Transcription factors can contribute to HERV activation by combining with the promoter region in 5'LTR. Activated HERV can be transcribed into both ncRNA and mRNA. For the latter, it can be further translated into proteins or peptides. HERV, human endogenous retrovirus; LTR, long terminal repeat; HIV, human immunodeficiency virus; KSHV, Kaposi's sarcoma-associated herpesvirus; nc, non-coding.

with bromodomain 4 increases histone methylation and suppresses HERVs in colorectal cancer by the regulation of histone methyltransferases, such as SET domain, bifurcated 1 (SETDB1) and Su(var)3-9 homologue 1 proteins, and subsequently inhibits tumor growth (72).

For histone methylation, the relationship between histone methylation and gene activity is intricate (63). Distinct lysine sites of methylation and methylation types may have different impacts on the turning 'on' and 'off' of genes (63). LSD1, a histone H3K4 demethylase increased the transcripts of HERVs via the demethylation of LTRs in the MCF-7 cell line (73). G9Ai, a histone methyltransferase inhibitor which can inhibit the catalytic reaction of methylation of histone $\mathrm{H} 3 \mathrm{~K} 9$ also increases the transcripts of HERV-Fc1 in ovarian A2780 and CAOV3 cell lines (74). Lysine residue 9 of histone $\mathrm{H} 3$ has 3 methylation types, including mono-, di- and tri-methylation (75). G9A is one of the histone methyltransferases that can catalyze mono-methylation and demethylation (74). There are other histone methyltransferases, such as SETDB1 (catalyzing di- and trimethylation) (76) and GLP (catalyzing mono- and di-methylation) (77), involved in silencing HERVs. For instance, it was recently found that the former enzyme, SETDB1, controls the stability of T helper 2 cells through catalyzing the trimethylation of H3K9 in HERV regions, which act as enhancers for T helper 1 genes (78). These histone methylations are associated with crucial proteins called Krüppel-associated box zinc finger proteins (KRAB-ZFP, also called KAP1 or TRIM28) (79). KRAB-ZFP contributes to histone and DNA methylation by combining with HERV LTRs leading to the HERVs becoming silent and regions of heterochromatin (79-81).

Environmental factors. Infection with tumor-associated viruses can regulate the expression of HERVs (38). The levels of HERVs were observed to be higher in HIV-infected patients compared with in healthy individuals (54). HIV-1 TAT protein serves an essential role in regulating almost 48 HERV-K proviruses in human peripheral blood lymphocytes (54). Two primary Kaposi's sarcoma-associated herpesvirus (KSHV)-encoded latent genes, the latency-associated nuclear antigen (LANA) and viral FADD-like interferon converting enzyme inhibitory protein $(v F L I P)$ activate HERV-K transcription via the MAPK pathway and NF- $\mathrm{KB}$ pathway, respectively (38). Additionally, the human T-cell leukemia virus-1 TAX protein activates HERV LTRs, especially HERV-W8 LTRs (82). Infection by the Epstein-Barr virus has been demonstrated to be an activator for the transactivation of HERV-K18 in B lymphoblastoid cell lines (83). The mechanisms of HERV activation by viruses are relatively clear whereas those by physical and chemical factors remain uncertain $(54,82,83)$. Hydroquinone (55), cupric ion (84), silver nanoparticles (85), and ultraviolet exposure (86), as well as hypoxia phenomenon (70) can influence the expression of HERVs in tumor cell lines. However, the underlying mechanism remains unknown (Fig. 2). 


\section{Dual opposing roles of HERVs in cancer}

Cancer-promoting effects and mechanisms of HERVs. Carcinogenesis is a complex process that involves the interplay between multiple genetic and environmental factors (87). Genetically, cellular proto-oncogene mutations like $R A S$ or the loss of function of cancer suppressor genes like $p 53$ can cause various types of cancer (including breast cancer and colon carcinoma) $(88,89)$. External factors, ionizing radiation, chemical carcinogens and viruses are also common cancerogenic substances $(54,55,86)$. Persistent viral infection is crucial for the pathogenesis of some kinds of cancer (90). For example, viral hepatitis caused by the hepatitis B virus can ultimately lead to liver cancer, and cervix uteri infected by human papillomavirus can develop into cervical cancer $(91,92)$. The fact that exogenous viruses can cause cancer has been extensively recognized (90). The present review will discuss the effects of endogenous retroviruses on cancer.

Immune surveillance is essential for hosts against tumors and HERV ENV proteins may facilitate carcinogenesis via immune suppression (93). Specific amino residues are necessary for the immunosuppressive effects of HERV ENV proteins, which means that not all HERV ENV proteins have this property (25). For instance, through immunogenicity and in vivo tumor-rejection assays, syncytin- 2 was identified as an immunosuppressive protein and contributed to tumor growth, but syncytin-1 did not have these characteristics (25). Using sequence alignment and the introduction of a mutation in these 2 syncytins, it was found that K 14 (lysine residue) within the immunosuppressive domain (ISU) may be a crucial amino residue for the immunosuppressive property of syncytin-2 (25). In addition, there are quite a few HERV ENV proteins with immunosuppressive properties, such as HERV-H, ERV3, HERV-P(b) and HERV-V ENV proteins $(25,94)$.

Nevertheless, how these proteins suppress host immunity remains unclear. Studies have demonstrated that HERV ENV proteins may suppress immunity via inhibiting the proliferation of $\mathrm{T}$ cells and alleviating lipopolysaccharide-induced immune activation $(25,95)$. Predicted DNA sequences $(\sim 1,000)$ of ENV ISU have indicated that ENV proteins may serve a more significant role in immunosuppression (96). In a murine model (using BALB/c mice), tumor growth was repressed when mice acquired active or passive immunization against the HK2 ENV protein $(97,98)$. Hence, targeting ENV proteins may be an effective future treatment for cancers with high expression levels of ENV proteins.

In general, the tumor-promoting effect of the ENV ISU domain may be a universal mechanism. In contrast, other mechanisms, such as activation of the ERK or Wnt signaling pathways, by which the env gene promotes tumorigenesis and cancer progression, vary by types of malignant tumors $(24,40)$.

Breast cancer. Compared with other types of cancer, the association between HK2 and breast cancer has been studied more comprehensively $(21,99)$. The expression of HK2 env transcripts and ENV proteins is increased in breast cancer (27), especially basal-like breast cancer subtype with $H$-RAS (wild-type) (21). In addition, antibodies against HK2 ENV proteins are detected in the blood of patients with early-stage breast cancer and the level of these antibodies in women decreases with age (99). The aforementioned antibodies may have value in the diagnosis of breast cancer. The presence of HK2 ENV proteins in patients with early-stage breast cancer implies that they supposedly serve a role in breast cancer initiation. An observational study by Mastrangelo et al (100) also indicated the cancer-promoting effects of HK2 ENV proteins. Epidemiological data indicates that the yellow fever vaccine 17D, which elicits cross-reactive immunity against HK2 ENV halved the incidence of breast cancer in women ranging from 40-54 years (100). The effect of preventing breast cancer would be improved by the use of vaccines against HK2 (101). Hence, developing antitumor vaccines based on HK2 ENV to prevent breast cancer may be promising.

The possible mechanisms through which HERVs enhance the carcinogenesis of breast cancer have been gradually unveiled. The activation of the ERK pathway and the downregulation of $\mathrm{p} 53$ protein caused by increased HK2 ENV protein were notable findings (40). The aforementioned findings support the view that the HK2 ENV protein may promote the carcinogenesis of breast cancer (40). p53 is a cancer suppressor gene whose mutation can induce a numerous cancers, such as lymphomas and sarcomas (102). Although a $R A S$ gene mutation is rare in breast cancer, the RAS/ERK pathway is highly activated in most breast cancers (103). Hyperactivation of the RAS/ERK pathway in breast cancer is partly induced by the elevated HK2 ENV protein (103). In addition, the cytoplasmic tail of the transmembrane subunit of the ENV protein is required for hyperactivation of the RAS/ERK pathway (104). This activation is accompanied by a strong upregulation of several downstream genes, including ETV4, ETV5, and EGRI, which promote cellular transformation (104). In breast cancer, upregulation of the HK2 ENV protein suppresses p53 (40). The suppressed $p 53$ gene may be another contributor to the HERV-related carcinogenesis of breast cancer. Epithelial to mesenchymal transition (EMT) is an important mechanism of cancer metastasis. Increased HK2 ENV protein enhances the invasion and migration abilities of breast cancer promoting the process of EMT (104). The underlying mechanism for the aforementioned phenomenon remains unclear.

Cell-cell fusion mediated by HERV-W and HERV-FRD ENV protein in cancer is weakly evidenced $(35,105)$. Both syncytin-1 and syncytin-2 serve a vital role in cytotrophoblast-cytotrophoblast fusion. Syncytin-1 is expressed and located at the cell membrane of breast cancer cells (105). It has been demonstrated that syncytin-1 promoted the fusion between breast cancer cells and endothelial cells by combining with ASCT-2, a cell membrane surface receptor for syncytin-1 (105). In line with this phenomenon in breast cancer, the fusion between choriocarcinoma cells and endothelial cells may be associated with syncytin-1 and HERV-Pb ENV (35). The fusion between endothelial cells and tumor cells mediated by HERV ENV may be observed in other kinds of cancer (106). There are two results of the fusion of healthy cells and cancer cells $(107,108)$. One is the common scenario where the hybrid formed cell may be a normal cell due to the activation of tumor suppressors produced by the normal parental cell (107). The other is that the hybrid formed cell acquires more aggressive properties compared with the parental cancer cell, although this possibility is rare (108). The characteristic of the hybrid formed cell fused by these 2 types 
of cancer cells and endothelial cells in research has not yet been identified (105). It may contribute to the invasion and metastasis of cancer if formed cells exhibit traits of cancer cells (108). Hence, this possible mechanism requires further explorations in carcinogenesis.

In addition to the ENV protein, non-coding RNA encoded by HERVs facilitates the progression of breast cancer, which may also be a contributing mechanism (109,110). ZMYND8 protein degradation promoting the proliferation and metastasis of triple-negative (estrogen receptor/progesterone receptor/HER2-negative) breast cancer is the second mechanism (110). ZMYND8 is a suppressor of metastasis-linked genes, such as Slug, CD44, EGFR and VEGFR (109). TROJAN, a HERV-derived long non-coding RNA is expressed exclusively in triple-negative breast cancer and promotes ZMYND8 degradation through ubiquitination (110). Hence, TROJAN may be a potential therapeutic target for triple-negative breast cancer.

Pancreatic cancer. Li et al (23) demonstrated the close relationship between pancreatic cancer and HK2 env gene. High expression of HK2 env is associated with stages IIB and III of pancreatic cancer (23). In addition, high expression of HK2 env is essential for cell proliferation, tumor growth, and metastasis (23). Similar to breast cancer, it has been observed that the RAS/ERK pathway and $p 53$ can also be regulated by HK2 env in pancreatic cancer (23). The distinction is that RAS mutation is common in pancreatic cancer and essential to its carcinogenesis (88). According to the best of our knowledge, the $R A S$ mutation does not serve a primary etiological role in breast cancer (111). Based on this point, it seems possible that the increased expression of HK2 env may serve a more critical role in the carcinogenesis of pancreatic cancer compared with breast cancer. In addition to activating the RAS/ERK pathway, the expression of HK2 env may also promote the proliferation of pancreatic cancer cells via activating the JNK/MAPK pathway (23).

Germ cell tumors. Human germ cells are the gateway through which ancestor retroviruses invaded humans and retained HERVs (2). It is plausible that HERVs may make a massive difference to the survival or function of germ cells (2). In seminoma, it was reported that syncytin-1 and its splicing transcribed by HERV-W env were increased due to DNA demethylation of its promoter (112). This suggests that HERVs are also activated in germ cell tumors. HERVs can cause the pathological lesions of germ cells and may induce cancer. For example, the regulator of expression encoded by corf (REC) protein encoded by type II HK2 env can induce precancerous lesions of classic seminoma in transgenic mice (29). It is hard to identify whether the rec gene is an oncogene in humans. On the one hand, the increased expression of REC protein in patients with seminoma has not yet been reported, and precancerous lesions unlike carcinoma in situ, are reversible lesions by definition (29). The underlying mechanism of REC-induced precancerous lesions also remains elusive. On the other hand, proteins interacting with REC have been found and they could serve a dominant role in the REC-related carcinogenesis of germ cell tumors (113).

The $c-M Y C$ gene is a proto-oncogene and overexpressed in various types of cancer, including hepatocellular carcinoma and gastric adenocarcinoma $(114,115)$. The REC protein can upregulate the expression of $c-M Y C$ via inhibiting promyelocytic leukemia zinc finger (PLZF), a tumor suppressor first found in promyelocytic leukemia and promote cell proliferation and survival (116). In addition, $c-M Y C$ modulated by the REC protein depends on 2 androgen receptor (AR) pathways (113). $\mathrm{AR}$ is an upstream activator of $c-M Y C$ (113). The REC protein can combine with AR and testicular zinc-finger protein and promote AR-induced transactivation (113). Another androgen receptor-dependent pathway is that REC binding with the human small glutamine-rich tetratricopeptide protein relieves the suppression of AR and activates the AR-dependent genes, such as $c-M Y C$ (117). Simultaneously, activated AR can promote the expression of the REC protein (117). The aforementioned findings indicate that the REC protein and AR may be mutually reinforcing (117). This 'vicious cycle' is proposed as the possible promotion of carcinogenesis (117).

Another protein encoded by type I HK2 env, nuclear protein of $9 \mathrm{kDa}$ (NP9), can also suppress the PLZF protein and activate the c-MYC gene (116). In addition, NP9 can interact with the ligand of NUMB protein $\mathrm{X}$, which is able to promote the degradation of NUMB protein (118). Decreased NUMB protein is usually required for increased NOTCH pathway activity (119). It is still unknown how NP9 affects carcinogenesis via the NOTCH pathway in germ cell tumors.

Leukemia. Upregulation of $N p 9$ mRNA expression was detected in patients with chronic lymphocytic leukemia compared with in healthy individuals (120). Chen et al (24) first identified NP9 as a potential oncogenic protein, providing new insights into the putative role that viruses play in human leukemias. Specifically, it was found that NP9 can increase the growth of human leukemia stem/progenitor cells by activating the $\beta$-catenin, ERK, AKT, and NOTCH1 pathways. Amongst these pathways, $\beta$-catenin has been reported as an essential protein for the survival and proliferation of CD34+ leukemia stem cells (121), and hyperactivation of the c-MYC/AKT pathway is sufficient to cause hematologic malignant tumors (122). Additionally, NP17 may be another oncogenic protein associated with refractory or relapsed leukemia (123).

Kaposi's sarcoma. Kaposi's sarcoma is a classic example that HERVs transactivated by exogenous virus infection can promote carcinogenesis (124). KSHV infection is an important cause of morbidity of Kaposi's sarcoma in patients with AIDS (125). The mechanism through which KSHV upregulates the expression of HERVs has been clarified as aforementioned. Increased NP9 induced by KSHV infection can enhance primary endothelial cell invasiveness via activating the CD147-A disintegrin and metalloproteinase with thrombospondin motifs 1 (ADAMTS1)/ADAMTS9 axis (38). In addition, the silencing of HK2 env can reduce the expression of vascular endothelial-derived growth factor, which is a prime pro-angiogenic cytokine in the invasion of primary endothelial cells triggered by KSHV (38).

Potential for the oncogenic role of HERVs. In summary, the aforementioned pathways and molecules are the possible mechanisms through which HERVs promote carcinogenesis. HK2 can promote carcinogenesis through a tiny number 
Table I. Molecular evidence for the oncogenic effect of HERV-derived molecules.

\begin{tabular}{|c|c|c|c|c|c|c|}
\hline First author, year & $\begin{array}{l}\text { Tumor } \\
\text { type }\end{array}$ & Group & Molecules & Molecular mechanism & Oncogenic effect & (Refs.) \\
\hline $\begin{array}{l}\text { Zhou et al, 2016; } \\
\text { Lemaitre et al, } 2017\end{array}$ & $\begin{array}{l}\text { Breast } \\
\text { cancer }\end{array}$ & HK2 & ENV & $\begin{array}{l}\text { Activated the MAPK } \\
\text { pathway and regulating } \\
\text { tumor-associated regulators } \\
\text { including p53, TGF- } \beta 1 \text {, } \\
\text { and MYC }\end{array}$ & $\begin{array}{l}\text { Promoted cell } \\
\text { proliferation, } \\
\text { migration, and } \\
\text { invasion }\end{array}$ & $\begin{array}{l}(40) \\
(104)\end{array}$ \\
\hline $\begin{array}{l}\text { Bjerregaard et al, } \\
2006\end{array}$ & $\begin{array}{l}\text { Breast } \\
\text { cancer }\end{array}$ & HERV-W & $\begin{array}{l}\text { ENV } \\
\text { (syncytin) }\end{array}$ & $\begin{array}{l}\text { Syncytin-ASCT2-mediated } \\
\text { fusion (ASCT2 is a receptor } \\
\text { for syncytin) }\end{array}$ & $\begin{array}{l}\text { Cancer-endothelial } \\
\text { cell fusion }\end{array}$ & $(105)$ \\
\hline Jin et al, 2019 & $\begin{array}{l}\text { Breast } \\
\text { cancer }\end{array}$ & HERV & TROJAN & $\begin{array}{l}\text { Bound to ZMYND8 and } \\
\text { then increased its } \\
\text { degradation }\end{array}$ & $\begin{array}{l}\text { Promoted tumor cell } \\
\text { proliferation and } \\
\text { metastasis }\end{array}$ & $(110)$ \\
\hline $\begin{array}{l}\text { Argaw-Denboba et al, } \\
2017\end{array}$ & Melanoma & HK2 & ENV & Unknown & $\begin{array}{l}\text { Promoted cell } \\
\text { phenotype-switching } \\
\text { and stemness } \\
\text { maintenance }\end{array}$ & $(136)$ \\
\hline Chen et al, 2013 & Leukemia & HK2 & ENV (NP9) & $\begin{array}{l}\text { Activated the WNT, ERK, } \\
\text { AKT, and NOTCH1 } \\
\text { pathways }\end{array}$ & $\begin{array}{l}\text { Promoted tumor } \\
\text { growth }\end{array}$ & (24) \\
\hline Denne et al, 2007 & $\begin{array}{l}\text { Germline } \\
\text { cancer }\end{array}$ & HK2 & $\begin{array}{l}\text { ENV (NP9 } \\
\text { and REC) }\end{array}$ & $\begin{array}{l}\text { De-repressed c-MYC via } \\
\text { inhibiting PLZF }\end{array}$ & $\begin{array}{l}\text { Promoted cell } \\
\text { proliferation }\end{array}$ & $(116)$ \\
\hline Li et al, 2017 & $\begin{array}{l}\text { Pancreatic } \\
\text { cancer }\end{array}$ & HK2 & ENV & $\begin{array}{l}\text { Influenced signal } \\
\text { transduction via the } \\
\text { RAS-ERK-RSK } \\
\text { pathway }\end{array}$ & $\begin{array}{l}\text { Promoted cell } \\
\text { proliferation, tumor, } \\
\text { growth } \\
\text { and metastasis }\end{array}$ & (23) \\
\hline Dai et al, 2018 & $\begin{array}{l}\text { Kaposi's } \\
\text { sarcoma }\end{array}$ & HK2 & ENV (NP9) & $\begin{array}{l}\text { Activated the } \\
\text { CD147-ADAMTS1/ } \\
\text { ADAMTS9 axis }\end{array}$ & $\begin{array}{l}\text { Promoted cell } \\
\text { proliferation and } \\
\text { invasion }\end{array}$ & $(38)$ \\
\hline
\end{tabular}

ADAMTS1/9, A disintegrin and metalloproteinase with thrombospondin motifs 1/9; ASCT2, alanine serine cysteine transporter 2; ENV, envelope; HK2, HERV-K HML-2; MAPK, mitogen-activated protein kinase; NP9, nuclear-protein of 9 kDa; PLZF, promyelocytic leukemia zinc finger; REC, regulator of expression encoded by corf; ZMYND8, zinc finger MYND-type containing 8.

of molecules, including ENV, NP9 and REC protein which maybe therapeutic targets in specific cancers, in contrast with numerous HERV groups $(38,104,116)$. Evaluating the individual contributions of these HERV molecules to carcinogenesis is difficult (29). Whether an aberrant expression of these HERV molecules occurs in the early stage of cancer or can be detected in cancer stem cells is vital for their roles in carcinogenesis. Anti-ENV antibodies are detected in patients with early stage breast cancer (99). NP9 protein can facilitate the growth of leukemia stem/progenitor cells as previously described. Numerous studies have indicated that these molecules are involved in significant molecular events in early carcinogenesis (Table I). More future studies should focus on this problem.

Cancer-suppressive effects and mechanisms of HERVs. Contrary to the immunosuppressive effects of HERVs, HERVs can activate immunity to inhibit cancer. An interesting phenomenon was observed: A higher immunogenic HERV level indicated increased immune infiltration, a more substantial fraction of $\mathrm{CD}^{+} \mathrm{T}$ cells and upregulation of the checkpoint pathway compared with a lower immunogenic ERV level in clear cell renal cell carcinoma (26). HERV products can activate innate immunity, cellular immunity, and humoral immunity in malignant tumors $(26,31,126)$. These immunological mechanisms stimulated by HERVs may have an impact on tumorigenesis and cancer progression (127-130). Cytotoxic T cell-mediated immunity can be induced by the HERV ENV protein in a few types of cancer, such as ovarian (31), breast cancer (127) and colorectal carcinoma (128). The performance of HERV-K-specific T cells resembles a classical cellular immune response (31). The proliferation of T cells, IFN- $\gamma$ products and HERV-K-specific cytotoxic T lymphocyte activity of lysing target cells is detected $(31,129)$. A similar situation occurs in colorectal carcinoma, where the activators are HERV-H ENV peptides (128). The HERV ENV protein can regulate the stimulatory activity of dendritic cells (DCs) and target $\mathrm{T}$ cells (95). In this process, DCs and $\mathrm{T}$ cells conjugate formation is affected by the HERV ENV protein in an unknown way (95). Additionally, H17, a peptide originating from HERV-H can facilitate EMT and can enrich pluripotent 
immunoregulatory $\mathrm{CD} 271^{+}$cells by activating the expression of CCL19, and serve a crucial role in the immune escape of tumor cells (130).

HERVs can stimulate B cell immunity and antibodies targeting HERV proteins are readily detectable in the blood of patients with tumors, such as breast cancer (126). Although it is hard to estimate the direct antitumor effect of these antibodies in patients, some antibody levels are associated with the tumor staging and predictors for prognosis, such as melanoma (131) and prostate tumors (132).

It has been clarified above that DNA and histone epigenetic modification can regulate the expression of HERVs. The activation of innate immunity of IFN-I signaling can be induced by epigenetic drugs, such as DNMTi and G9Ai, possibly mediated by increased HERV transcripts in ovarian cancer $(74,133,134)$. An increase in $\mathrm{CD}^{+} \mathrm{T}$ cells accompanies this process (134). In addition, DNMTi can activate IFN-III signaling with increased HERV transcripts in colorectal cancer (134). The aforementioned epigenetic drugs can induce 'viral mimicry' effects by the possible production of HERV expression products that can lead to stimulation of the viral defense response and promotion of cell death (135). DNA hypomethylation of HERV LTRs, regardless of the tumor-intrinsic or pharmacologically-induced origin may result in antitumor effects $(74,135)$.

\section{Conclusion}

Existing evidence indicates that HERVs are likely to promote carcinogenesis as accessory factors rather than causative facto rs $(23,24,38,40,104,105,116,136)$. HERVs can activate multiple oncogenic signaling pathways and inhibit tumor suppressor genes. The effects of HERVs activating or suppressing immunity could reflect a profound interaction between host and ancient exogenous or endogenous retroviruses whose total effect may promote carcinogenesis. Based on existing knowledge, HK2 plays prime cancer-promoting effects among HERVs. HERV env gene provides a bridge between the HERVs and their roles in cancer. Besides, non-coding RNAs transcribed by HERVs, such as TROJAN are also worthy of attention. The regulatory mechanisms of HERVs are complex and partly vary by HERV groups. Nowadays, studies regarding HERVs are hampered due to a plethora of transcribed HERV RNAs in cancer and the lack of specific commercial antibodies (137). The emerging high-throughput RNA-sequencing technique may demonstrate a more explicit expression profile of HERVs and expand possible roles in cancer $(137,138)$. Insufficient knowledge regarding HERV genes, their highly complex pattern of activation, and transcriptional and posttranscriptional regulation hinders the ability to study the mechanistic role of HERVs in numerous cancers. Efforts in exploring ways to interfere with HERVs during carcinogenesis are still at an early stage. Noteworthily, the aforementioned HERV molecules may be potential targets in the treatment of cancer. In addition, HERVs can induce immune responses of the host. Cancer prevention may be possible via the use of vaccines against HERVs, since HERVs serve crucial roles in early cancer as postulated. There are promising leads that will provide an improved understanding of how HERVs contribute to cancer $(110,139,140)$. This knowledge of HERVs will lead to it being used in translational research and will guide researchers to develop vaccines against HERVs preventing cancers.

\section{Acknowledgements}

The authors would like to thank Professor Riccardo Fodde (Department of Pathology, Erasmus MC Cancer Institute, Erasmus University Medical Center, Rotterdam, The Netherlands) for critically reading the manuscript and providing valuable suggestions.

\section{Funding}

The present study was funded by the National Natural Science Foundation of China (grant no. 81500115), the Natural Science Foundation of Zhejiang Province (grant no. LQ15H080001) and Zhengshu Elite Scholarship.

\section{Availability of data and materials}

Not applicable.

\section{Authors' contributions}

YG contributed to the conceptualization and visualization of the study, writing the original draft and reviewing and editing the manuscript. TC contributed to the conceptualization, reviewing and editing of the manuscript, supervision, project administration and funding acquisition. XFY contributed to reviewing and editing of the manuscript, supervision and project administration. All authors read and approved the final manuscript.

\section{Ethics approval and consent to participate}

Not applicable.

\section{Patient consent for publication}

Not applicable.

\section{Competing interests}

The authors declare that they have no competing interests.

\section{References}

1. LanderES,Linton LM, Birren B, Nusbaum C, Zody MC, Baldwin J, Devon K, Dewar K, Doyle M, FitzHugh W, et al: Initial sequencing and analysis of the human genome. Nature 409: 860-921, 2001.

2. Bannert $\mathrm{N}$ and Kurth R: The evolutionary dynamics of human endogenous retroviral families. Annu Rev Genomics Hum Genet 7: 149-173, 2006.

3. Hohn O, Hanke K and Bannert N: HERV-K(HML-2), the best preserved family of HERVs: Endogenization, expression, and implications in health and disease. Front Oncol 3: 246, 2013.

4. Garcia-Montojo M, Doucet-O'Hare T, Henderson L and Nath A: Human endogenous retrovirus-K (HML-2): A comprehensive review. Crit Rev Microbiol 44: 715-738, 2018.

5. Henzy JE and Coffin JM: Betaretroviral envelope subunits are noncovalently associated and restricted to the mammalian class. J Virol 87: 1937-1946, 2013.

6. Schommer S, Sauter M, Kräusslich HG, Best B and Mueller-Lantzsch N: Characterization of the human endogenous retrovirus K proteinase. J Gen Virol 77: 375-379, 1996.

7. George M, Schwecke T, Beimforde N, Hohn O, Chudak C, Zimmermann A, Kurth R, Naumann D and Bannert N: Identification of the protease cleavage sites in a reconstituted Gag polyprotein of an HERV-K(HML-2) element. Retrovirology 8: 30, 2011. 
8. Kjellman C, Sjögren HO and Widegren B: HERV-F, a new group of human endogenous retrovirus sequences. J Gen Virol 80: 2383-2392, 1999.

9. Kremer D, Gruchot J, Weyers V, Oldemeier L, Göttle P, Healy L, Ho Jang J, Kang T Xu Y, Volsko C, Dutta R, et al: pHERV-W envelope protein fuels microglial cell-dependent damage of myelinated axons in multiple sclerosis. Proc Natl Acad Sci USA 116: 15216-15225, 2019.

10. Li W, Lee MH, Henderson L, Tyagi R, Bachani M, Steiner J, Campanac E, Hoffman DA, von Geldern G, Johnson K, et al: Human endogenous retrovirus-K contributes to motor neuron disease. Sci Transl Med 7: 307ra153, 2015.

11. Terry SN, Manganaro L, Cuesta-Dominguez A, Brinzevich D, Simon V and Mulder LCF: Expression of HERV-K108 envelope interferes with HIV-1 production. Virology 509: 52-59, 2017.

12. Monde K, Terasawa H, Nakano Y, Soheilian F, Nagashima K, Maeda Y and Ono A: Molecular mechanisms by which HERV-K Gag interferes with HIV-1 Gag assembly and particle infectivity. Retrovirology 14: 27, 2017.

13. Huang WJ, Liu ZC, Wei W, Wang GH, Wu JG and Zhu F: Human endogenous retroviral pol RNA and protein detected and identified in the blood of individuals with schizophrenia. Schizophr Res 83: 193-199, 2006.

14. Yao Y, Schröder J, Nellåker C, Bottmer C, Bachmann S, Yolken RH and Karlsson $\mathrm{H}$ : Elevated levels of human endogenous retrovirus-W transcripts in blood cells from patients with first episode schizophrenia. Genes Brain Behav 7: 103-112, 2008.

15. Vargas A, Toufaily C, LeBellego F, Rassart E, Lafond J and Barbeau B: Reduced expression of both syncytin 1 and syncytin 2 correlates with severity of preeclampsia. Reprod Sci 18 : 1085-1091, 2011

16. Levet S, Charvet B, Bertin A, Deschaumes A, Perron H and Hober D: Human endogenous retroviruses and type 1 diabetes. Curr Diab Rep 19: 141, 2019.

17. Nogueira MA, Gavioli CF, Pereira NZ, de Carvalho GC, Domingues R, Aoki V and Sato MN: Human endogenous retrovirus expression is inversely related with the up-regulation of interferon-inducible genes in the skin of patients with lichen planus. Arch Dermatol Res 307: 259-264, 2015.

18. Ariza ME and Williams MV: A human endogenous retrovirus K dUTPase triggers a TH1, TH17 cytokine response: Does it have a role in psoriasis? J Invest Dermatol 131: 2419-2427, 2011.

19. Fali T, Le Dantec C, Thabet Y, Jousse S, Hanrotel C, Youinou P, Brooks WH, Perl A and Renaudineau Y: DNA methylation modulates HRES1/p28 expression in B cells from patients with Lupus. Autoimmunity 47: 265-271, 2014.

20. Reynier F, Verjat T, Turrel F, Imbert PE, Marotte H, Mougin B and Miossec P: Increase in human endogenous retrovirus HERV-K (HML-2) viral load in active rheumatoid arthritis Scand J Immunol 70: 295-299, 2009.

21. Johanning GL, Malouf GG, Zheng X, Esteva FJ, Weinstein JN Wang-Johanning $\mathrm{F}$ and $\mathrm{Su} \mathrm{X}$ : Expression of human endogenous retrovirus- $\mathrm{K}$ is strongly associated with the basal-like breast cancer phenotype. Sci Rep 7: 41960, 2017.

22. Ma W, Hong Z, Liu H, Chen X, Ding L, Liu Z, Zhou F and Yuan Y: Human Endogenous retroviruses-K (HML-2) expression is correlated with prognosis and progress of hepatocellular carcinoma. Biomed Res Int 2016: 8201642, 2016.

23. Li M, Radvanyi L, Yin B, Rycaj K, Li J, Chivukula R, Lin K, $\mathrm{Lu}$ Y, Shen J, Chang DZ, et al: Downregulation of human endogenous retrovirus type K (HERV-K) Viral env RNA in pancreatic cancer cells decreases cell proliferation and tumor growth. Clin Cancer Res 23: 5892-5911, 2017.

24. Chen T, Meng Z, Gan Y, Wang X, Xu F, Gu Y, Xu X, Tang J, Zhou $\mathrm{H}$, Zhang $\mathrm{X}$, et al: The viral oncogene Np9 acts as a critical molecular switch for co-activating $\beta$-catenin, ERK, Akt and Notch1 and promoting the growth of human leukemia stem/progenitor cells. Leukemia 27: 1469-1478, 2013.

25. Mangeney M, Renard M, Schlecht-Louf G, Bouallaga I, Heidmann O, Letzelter C, Richaud A, Ducos B and Heidmann T: Placental syncytins: Genetic disjunction between the fusogenic and immunosuppressive activity of retroviral envelope proteins. Proc Natl Acad Sci USA 104: 20534-20539, 2007.

26. Panda A, de Cubas AA, Stein M, Riedlinger G, Kra J, Mayer T, Smith CC, Vincent BG, Serody JS, Beckermann KE, et al: Endogenous retrovirus expression is associated with response to immune checkpoint blockade in clear cell renal cell carcinoma. JCI Insight 3: e121522, 2018
27. Tavakolian S, Goudarzi $\mathrm{H}$ and Faghihloo E: Evaluating the expression level of HERV-K env, np9, rec and gag in breast tissue. Infect Agent Cancer 14: 42, 2019.

28. Ibba G, Piu C, Uleri E, Serra C and Dolei A: Disruption by SaCas9 endonuclease of HERV-Kenv, a retroviral gene with oncogenic and neuropathogenic potential, inhibits molecules involved in cancer and amyotrophic lateral sclerosis. Viruses 10: $412,2018$.

29. Galli UM, Sauter M, Lecher B, Maurer S, Herbst H, Roemer K and Mueller-Lantzsch N: Human endogenous retrovirus rec interferes with germ cell development in mice and may cause carcinoma in situ, the predecessor lesion of germ cell tumors. Oncogene 24: 3223-3228, 2005

30. Kreimer U, Schulz WA, Koch A, Niegisch G and Goering W: HERV-K and LINE-1 DNA methylation and reexpression in urothelial carcinoma. Front Oncol 3: 255, 2013.

31. Rycaj K, Plummer JB, Yin B, Li M, Garza J, Radvanyi L, Ramondetta LM, Lin K, Johanning GL, Tang DG and Wang-Johanning F: Cytotoxicity of human endogenous retrovirus K-specific T cells toward autologous ovarian cancer cells. Clin Cancer Res 21: 471-483, 2015.

32. Zare M, Mostafaei S, Ahmadi A, Azimzadeh Jamalkandi S, Abedini A, Esfahani-Monfared Z, Dorostkar R and Saadati M: Human endogenous retrovirus env genes: Potential blood biomarkers in lung cancer. Microb Pathog 115: 189-193, 2018.

33. Bergallo M, Montanari P, Mareschi K, Merlino C, Berger M, Bini I, Daprà V, Galliano I and Fagioli F: Expression of the pol gene of human endogenous retroviruses HERV-K and -W in leukemia patients. Arch Virol 162: 3639-3644, 2017.

34. Barth M, Gröger V, Cynis H and Staege MS: Identification of human endogenous retrovirus transcripts in Hodgkin Lymphoma cells. Mol Biol Rep 46: 1885-1893, 2019.

35. Aagaard L, Bjerregaard B, Kjeldbjerg AL, Pedersen FS, Larsson LI and Rossi JJ: Silencing of endogenous envelope genes in human choriocarcinoma cells shows that envPb1 is involved in heterotypic cell fusions. J Gen Virol 93: 1696-1699, 2012.

36. Liang Q, Xu Z, Xu R, Wu L and Zheng S: Expression patterns of non-coding spliced transcripts from human endogenous retrovirus HERV-H elements in colon cancer. PLoS One 7: e29950, 2012.

37. Giebler M, Staege MS, Blauschmidt S, Ohm LI, Kraus M, Würl P, Taubert H and Greither T: Elevated HERV-K expression in soft tissue sarcoma is associated with worsened relapse-free survival. Front Microbiol 9: 211, 2018.

38. Dai L, Del Valle L, Miley W, Whitby D, Ochoa AC, Flemington EK and Qin Z: Transactivation of human endogenous retrovirus K (HERV-K) by KSHV promotes Kaposi's sarcoma development. Oncogene 37: 4534-4545, 2018.

39. Montesion M, Bhardwaj N, Williams ZH, Kuperwasser C and Coffin JM: Mechanisms of HERV-K (HML-2) transcription during human mammary epithelial cell transformation. J Virol 92: e01258-17, 2018.

40. Zhou F, Li M, Wei Y, Lin K, Lu Y, Shen J, Johanning GL and Wang-Johanning F: Activation of HERV-K Env protein is essential for tumorigenesis and metastasis of breast cancer cells. Oncotarget 7: 84093-84117, 2016.

41. Chan SM, Sapir T, Park SS, Rual JF, Contreras-Galindo R, Reiner O and Markovitz DM: The HERV-K accessory protein $\mathrm{Np} 9$ controls viability and migration of teratocarcinoma cells. PLoS One 14: e0212970, 2019.

42. van de Lagemaat LN, Medstrand P and Mager DL: Multiple effects govern endogenous retrovirus survival patterns in human gene introns. Genome Biol 7: R86, 2006.

43. Lee $Y$ and Rio DC: Mechanisms and regulation of alternative pre-mRNA splicing. Annu Rev Biochem 84: 291-323, 2015.

44. Leib-Mösch C, Haltmeier M, Werner T, Geigl EM, Brack-Werner R, Francke U, Erfle V and Hehlmann R: Genomic distribution and transcription of solitary HERV-K LTRs. Genomics 18: 261-269, 1993.

45. Ng KW, Attig J, Young GR, Ottina E, Papamichos SI, Kotsianidis I and Kassiotis G: Soluble PD-L1 generated by endogenous retroelement exaptation is a receptor antagonist. Elife 8: e50256, 2019.

46. Hassounah NB, Malladi VS, Huang Y, Freeman SS, Beauchamp EM, Koyama S, Souders N, Martin S, Dranoff G, Wong KK, et al: Identification and characterization of an alternative cancer-derived PD-L1 splice variant. Cancer Immunol Immunother 68: 407-420, 2019. 
47. Bassani-Sternberg M, Bräunlein E, Klar R, Engleitner T, Sinitcyn P, Audehm S, Straub M, Weber J, Slotta-Huspenina J, Specht K, et al: Direct identification of clinically relevant neoepitopes presented on native human melanoma tissue by mass spectrometry. Nat Commun 7: 13404, 2016.

48. Attig J, Young GR, Hosie L, Perkins D, Encheva-Yokoya V, Stoye JP, Snijders AP, Ternette N and Kassiotis G: LTR retroelement expansion of the human cancer transcriptome and immunopeptidome revealed by de novo transcript assembly. Genome Res 29: 1578-1590, 2019.

49. Laumont CM, Daouda T, Laverdure JP, Bonneil É, Caron-Lizotte O, Hardy MP, Granados DP, Durette C, Lemieux S, Thibault $\mathrm{P}$ and Perreault C: Global proteogenomic analysis of human MHC class I-associated peptides derived from non-canonical reading frames. Nat Commun 7: 10238, 2016

50. Zhu Y, Orre LM, Johansson HJ, Huss M, Boekel J, Vesterlund M, Fernandez-Woodbridge A, Branca RMM and Lehtiö J: Discovery of coding regions in the human genome by integrated proteogenomics analysis workflow. Nat Commun 9: 903, 2018.

51. Montesion M, Williams ZH, Subramanian RP, Kuperwasser C and Coffin JM: Promoter expression of HERV-K (HML-2) provirus-derived sequences is related to LTR sequence variation and polymorphic transcription factor binding sites. Retrovirology 15: 57, 2018.

52. Knossl M, Lower R and Lower J: Expression of the human endogenous retrovirus HTDV/HERV-K is enhanced by cellular transcription factor YY1. J Virol 73: 1254-1261, 1999.

53. Ohtani H, Liu M, Zhou W, Liang G and Jones PA: Switching roles for DNA and histone methylation depend on evolutionary ages of human endogenous retroviruses. Genome Res 28: 1147-1157, 2018.

54. Gonzalez-Hernandez MJ, Cavalcoli JD, Sartor MA, Contreras-Galindo R, Meng F, Dai M, Dube D, Saha AK, Gitlin SD, Omenn GS, et al: Regulation of the human endogenous retrovirus K (HML-2) transcriptome by the HIV-1 Tat protein. J Virol 88: 8924-8935, 2014.

55. Conti A, Rota F, Ragni E, Favero C, Motta V, Lazzari L, Bollati V, Fustinoni S and Dieci G: Hydroquinone induces DNA hypomethylation-independent overexpression of retroelements in human leukemia and hematopoietic stem cells. Biochem Biophys Res Commun 474: 691-695, 2016.

56. Subramanian RP, Wildschutte JH, Russo C and Coffin JM: Identification, characterization, and comparative genomic distribution of the HERV-K (HML-2) group of human endogenous retroviruses. Retrovirology 8: 90, 2011.

57. Liang Q, Ding J, Xu R, Xu Z and Zheng S: Identification of a novel human endogenous retrovirus and promoter activity of its 5' U3. Biochem Biophys Res Commun 382: 468-472, 2009.

58. Fuchs NV, Kraft M, Tondera C, Hanschmann KM, Löwer J and Löwer R: Expression of the human endogenous retrovirus (HERV) group HML-2/HERV-K does not depend on canonical promoter elements but is regulated by transcription factors $\mathrm{Sp} 1$ and Sp3. J Virol 85: 3436-3448, 2011.

59. Yu H, Liu T, Zhao Z, Chen Y, Zeng J, Liu S and Zhu F: Mutations in 3'-long terminal repeat of HERV-W family in chromosome 7 upregulate syncytin-1 expression in urothelial cell carcinoma of the bladder through interacting with c-Myb. Oncogene 33: 3947-3958, 2014

60. Katoh I, Mírová A, Kurata S, Murakami Y, Horikawa K, Nakakuki N, Sakai T, Hashimoto K, Maruyama A, Yonaga T, et al: Activation of the long terminal repeat of human endogenous retrovirus $\mathrm{K}$ by melanoma-specific transcription factor MITF-M. Neoplasia 13: 1081-1092, 2011.

61. Stacey KJ and Sagulenko V: A clear link between endogenous retroviral LTR activity and Hodgkin's lymphoma. Cell Res 20 869-871, 2010

62. Kriaucionis S and Tahiliani M: Expanding the epigenetic landscape: Novel modifications of cytosine in genomic DNA. Cold Spring Harb Perspect Biol 6: a018630, 2014.

63. Brookes E and Shi Y: Diverse epigenetic mechanisms of human disease. Annu Rev Genet 48: 237-268, 2014.

64. Lavie L, Kitova M, Maldener E, Meese E and Mayer J: CpG methylation directly regulates transcriptional activity of the human endogenous retrovirus family HERV-K(HML-2). J Virol 79: 876-883, 2005.

65. Florl AR, Löwer R, Schmitz-Dräger BJ and Schulz WA: DNA methylation and expression of LINE-1 and HERV-K provirus sequences in urothelial and renal cell carcinomas. Br J Cancer 80 : $1312-1321,1999$
66. Menendez L, Benigno BB and McDonald JF: L1 and HERV-W retrotransposons are hypomethylated in human ovarian carcinomas. Mol Cancer 3: 12, 2004

67. Stengel S, Fiebig U, Kurth R and Denner J: Regulation of human endogenous retrovirus-K expression in melanomas by CpG methylation. Genes Chromosomes Cancer 49: 401-411, 2010.

68. Strissel PL, Ruebner M, Thiel F, Wachter D, Ekici AB, Wolf F, Thieme F, Ruprecht K, Beckmann MW and Strick R: Reactivation of codogenic endogenous retroviral (ERV) envelope genes in human endometrial carcinoma and prestages: Emergence of new molecular targets. Oncotarget 3: 1204-1219, 2012.

69. Hu L, Uzhameckis D, Hedborg F and Blomberg J: Dynamic and selective HERV RNA expression in neuroblastoma cells subjected to variation in oxygen tension and demethylation. APMIS 124: 140-149, 2016.

70. Bannister AJ and Kouzarides T: Regulation of chromatin by histone modifications. Cell Res 21: 381-395, 2011.

71. Krönung SK, Beyer U, Chiaramonte ML, Dolfini D, Mantovani R and Dobbelstein M: LTR12 promoter activation in a broad range of human tumor cells by HDAC inhibition. Oncotarget 7: 33484-33497, 2016.

72. Rajagopalan D, Tirado-Magallanes R, Bhatia SS, Teo WS Sian S, Hora S, Lee KK, Zhang Y, Jadhav SP, Wu Y, et al: TIP60 represses activation of endogenous retroviral elements. Nucleic Acids Res 46: 9456-9470, 2018.

73. Sheng W, LaFleur MW, Nguyen TH, Chen S, Chakravarthy A, Conway JR, Li Y, Chen H, Yang H, Hsu PH, et al: LSD1 ablation stimulates anti-tumor immunity and enables checkpoint blockade. Cell 174: 549-563.e19, 2018.

74. Liu M, Thomas SL, DeWitt AK, Zhou W, Madaj ZB, Ohtani H, Baylin SB, Liang G and Jones PA: Dual inhibition of DNA and histone methyltransferases increases viral mimicry in ovarian cancer cells. Cancer Res 78: 5754-5766, 2018

75. Audergon PN, Catania S, Kagansky A, Tong P, Shukla M, Pidoux AL and Allshire RC: Epigenetics. Restricted epigenetic inheritance of H3K9 methylation. Science 348: 132-135, 2015.

76. Matsui T, Leung D, Miyashita H, Maksakova IA, Miyachi H, Kimura H, Tachibana M, Lorincz MC and Shinkai Y: Proviral silencing in embryonic stem cells requires the histone methyltransferase ESET. Nature 464: 927-931, 2010.

77. Sharma S, Gerke DS, Han HF, Jeong S, Stallcup MR, Jones PA and Liang G: Lysine methyltransferase G9a is not required for DNMT3A/3B anchoring to methylated nucleosomes and maintenance of DNA methylation in somatic cells. Epigenetics Chromatin 5: 3, 2012.

78. Adoue V, Binet B, Malbec A, Fourquet J, Romagnoli P, van Meerwijk JPM, Amigorena S and Joffre OP: The histone methyltransferase SETDB1 controls T helper cell lineage integrity by repressing endogenous retroviruses. Immunity 50: 629-644.e8, 2019.

79. Imbeault M, Helleboid P-Y and Trono D: KRAB zinc-finger proteins contribute to the evolution of gene regulatory networks. Nature 543: 550-554, 2017.

80. Thomas JH and Schneider S: Coevolution of retroelements and tandem zinc finger genes. Genome Res 21: 1800-1812, 2011.

81. Voon HPJ and Gibbons RJ: Maintaining memory of silencing at imprinted differentially methylated regions. Cell Mol Life Sci 73: 1871-1879, 2016

82. Toufaily C, Landry S, Leib-Mosch C, Rassart E and Barbeau B: Activation of LTRs from different human endogenous retrovirus (HERV) families by the HTLV-1 tax protein and T-cell activators. Viruses 3: 2146-2159, 2011.

83. Sutkowski N, Conrad B, Thorley-Lawson DA and Huber BT: Epstein-Barr virus transactivates the human endogenous retrovirus HERV-K18 that encodes a superantigen. Immunity 15: 579-589, 2001.

84. Karimi A, Sheervalilou R and Kahroba H: A new insight on activation of human endogenous retroviruses (HERVs) in malignant melanoma upon exposure to CuSO4. Biol Trace Elem Res 191: 70-74, 2019.

85. Alqahtani S, Promtong P, Oliver AW, He XT, Walker TD, Povey A, Hampson L and Hampson IN: Silver nanoparticles exhibit size-dependent differential toxicity and induce expression of syncytin-1 in FA-AML1 and MOLT-4 leukaemia cell lines. Mutagenesis 31: 695-702, 2016.

86. Reiche J, Pauli G and Ellerbrok H: Differential expression of human endogenous retrovirus $\mathrm{K}$ transcripts in primary human melanocytes and melanoma cell lines after UV irradiation. Melanoma Res 20: 435-440, 2010. 
87. Tsilimigras MC, Fodor A and Jobin C: Carcinogenesis and therapeutics: The microbiota perspective. Nat Microbiol 2: 17008, 2017.

88. Simanshu DK, Nissley DV and McCormick F: RAS proteins and their regulators in human disease. Cell 170: 17-33, 2017

89. Vieler M and Sanyal S: p53 Isoforms and their implications in cancer. Cancers (Basel) 10: 288, 2018.

90. McLane LM, Abdel-Hakeem MS and Wherry EJ: CD8 T cell exhaustion during chronic viral infection and cancer. Annu Rev Immunol 37: 457-495, 2019.

91. Chan SL, Wong VW, Qin S and Chan HL: Infection and cancer: The case of hepatitis B. J Clin Oncol 34: 83-90, 2016.

92. Roden RBS and Stern PL: Opportunities and challenges for human papillomavirus vaccination in cancer. Nat Rey Cancer 18: 240-254, 2018.

93. Cianciolo GJ, Copeland TD, Oroszlan S and Snyderman R: Inhibition of lymphocyte proliferation by a synthetic peptide homologous to retroviral envelope proteins. Science 230 453-455, 1985.

94. Mangeney M, de Parseval N, Thomas G and Heidmann T: The full-length envelope of an HERV-H human endogenous retrovirus has immunosuppressive properties. J Gen Virol 82: 2515-2518, 2001.

95. Hummel J, Kämmerer U, Müller N, Avota E and Schneider-Schaulies S: Human endogenous retrovirus envelope proteins target dendritic cells to suppress T-cell activation. Eur J Immunol 45: 1748-1759, 2015.

96. Lv H, Han J, Liu J, Zheng J, Zhong D and Liu R: ISDTool: A computational model for predicting immunosuppressive domain of HERVs. Comput Biol Chem 49: 45-50, 2014.

97. Kraus B, Fischer K, Büchner SM, Wels WS, Löwer R, Sliva K and Schnierle BS: Vaccination directed against the human endogenous retrovirus-K envelope protein inhibits tumor growth in a murine model system. PLoS One 8: e72756, 2013.

98. Wang-Johanning F, Rycaj K, Plummer JB, Li M, Yin B, Frerich K, Garza JG, Shen J, Lin K, Yan P, et al: Immunotherapeutic potential of anti-human endogenous retrovirus-K envelope protein antibodies in targeting breast tumors. J Natl Cancer Inst 104: 189-210, 2012.

99. Kim HJ, Moon BI, Lee JW, Kim SC and Kim HJ: Age-related reduction of antibody response against the human endogenous retrovirus K envelope in women. Oncotarget 7: 17327-17337, 2016.

100. Mastrangelo G, Pavanello S, Fadda E, Buja A and Fedeli U: Yellow fever vaccine 17D administered to healthy women aged between 40 and 54 years halves breast cancer risk: An observational study. Eur J Cancer Prev 27: 303-309, 2018

101. Zhou F, Krishnamurthy J, Wei Y,Li M, Hunt K, Johanning GL, Cooper LJ and Wang-Johanning F: Chimeric antigen receptor $\mathrm{T}$ cells targeting HERV-K inhibit breast cancer and its metastasis through downregulation of Ras. Oncoimmunology 4 e1047582, 2015.

102. Wang Z, Zheng Y, Park HJ, Li J, Carr JR, Chen YJ, Kiefer MM, Kopanja D, Bagchi S, Tyner AL and Raychaudhuri $\mathrm{P}$ Targeting FoxM1 effectively retards p53-null lymphoma and sarcoma. Mol Cancer Ther 12: 759-767, 2013.

103. von Lintig FC, Dreilinger AD, Varki NM, Wallace AM, Casteel DE and Boss GR: Ras activation in human breast cancer. Breast Cancer Res Treat 62: 51-62, 2000.

104.Lemaître C, Tsang J, Bireau C, Heidmann T and Dewannieux M: A human endogenous retrovirus-derived gene that can contribute to oncogenesis by activating the ERK pathway and inducing migration and invasion. PLoS Pathog 13: e1006451, 2017.

105. Bjerregaard B, Holck S, Christensen IJ and Larsson LI: Syncytin is involved in breast cancer-endothelial cell fusions. Cell Mol Life Sci 63: 1906-1911, 2006.

106.Duelli D and Lazebnik Y: Cell fusion: A hidden enemy? Cancer Cell 3: 445-448, 2003.

107. Anderson MJ and Stanbridge EJ: Tumor suppressor genes studied by cell hybridization and chromosome transfer. FASEB J 7: 826-833, 1993

108. Köhler G and Milstein C: Continuous cultures of fused cells secreting antibody of predefined specificity. Nature 256 495-497, 1975.

109. Li N, Li Y, Lv J, Zheng X, Wen H, Shen H, Zhu G, Chen TY, Dhar SS, Kan PY, et al: ZMYND8 reads the dual histone mark H3K4me1-H3K14ac to antagonize the expression of metastasis-linked genes. Mol Cell 63: 470-484, 2016.
110. Jin X, Xu XE, Jiang YZ,Liu YR, Sun W, Guo YJ, Ren YX,Zuo WJ, $\mathrm{Hu} \mathrm{X}$, Huang SL, et al: The endogenous retrovirus-derived long noncoding RNA TROJAN promotes triple-negative breast cancer progression via ZMYND8 degradation. Sci Adv 5: eaat9820, 2019

111. Galiè M: RAS as supporting actor in breast cancer. Front Oncol 9: 1199, 2019.

112. Kaufmann S, Sauter M, Schmitt M, Baumert B, Best B, Boese A, Roemer K and Mueller-Lantzsch N: Human endogenous retrovirus protein $\mathrm{Rec}$ interacts with the testicular zinc-finger protein and androgen receptor. J Gen Virol 91: 1494-1502, 2010.

113. Benešová $M$, Trejbalová $K$, Kovářová $D$, Vernerová $Z$, Hron T, Kučerová D and Hejnar J: DNA hypomethylation and aberrant expression of the human endogenous retrovirus ERVWE1/syncytin-1 in seminomas. Retrovirology 14: 20, 2017.

114. Jiang B, Yang B, Wang Q, Zheng X, Guo Y and Lu W: lncRNA PVT1 promotes hepatitis B virus-positive liver cancer progression by disturbing histone methylation on the c-Myc promoter. Oncol Rep 43: 718-726, 2020.

115. de Souza CR, Leal MF, Calcagno DQ, Costa Sozinho EK, Borges Bdo N, Montenegro RC, Dos Santos AK, Dos Santos SE, Ribeiro HF, Assumpção PP, et al: MYC deregulation in gastric cancer and its clinicopathological implications. PLoS One 8: e64420, 2013

116. Denne M, Sauter M, Armbruester V, Licht JD, Roemer K and Mueller-Lantzsch N: Physical and functional interactions of human endogenous retrovirus proteins $\mathrm{Np} 9$ and rec with the promyelocytic leukemia zinc finger protein. J Virol 81: 5607-5616, 2007.

117. Hanke K, Chudak C, Kurth R and Bannert N: The Rec protein of HERV-K(HML-2) upregulates androgen receptor activity by binding to the human small glutamine-rich tetratricopeptide repeat protein (hSGT). Int J Cancer 132: 556-567, 2013

118. Armbruester V, Sauter M, Roemer K, Best B, Hahn S, Nty A, Schmid A, Philipp S, Mueller A and Mueller-Lantzsch N: Np9 protein of human endogenous retrovirus $\mathrm{K}$ interacts with ligand of numb protein X. J Virol 78: 10310-10319, 2004.

119. Shao X, Ding Z, Zhao M, Liu K, Sun H, Chen J, Liu X, Zhang Y, Hong Y, Li H and Li H: Mammalian Numb protein antagonizes Notch by controlling postendocytic trafficking of the Notch ligand Delta-like 4. J Biol Chem 292: 20628-20643, 2017.

120. Fischer S, Echeverría N, Moratorio G, Landoni AI, Dighiero G, Cristina J, Oppezzo P and Moreno P: Human endogenous retrovirus np9 gene is over expressed in chronic lymphocytic leukemia patients. Leuk Res Rep 3: 70-72, 2014.

121. Hu Y, Chen Y, Douglas L and Li S: beta-Catenin is essential for survival of leukemic stem cells insensitive to kinase inhibition in mice with BCR-ABL-induced chronic myeloid leukemia. Leukemia 23: 109-116, 2009.

122. Polak R and Buitenhuis M: The PI3K/PKB signaling module as key regulator of hematopoiesis: Implications for therapeutic strategies in leukemia. Blood 119: 911-923, 2012.

123. Wu B, Gan Y, Xu Y, Wu Z, Xu G, Wang P, Wang C, Meng Z, $\mathrm{Li} \mathrm{M}$, Zhang J, et al: Identification of the novel Np17 oncogene in human leukemia. Aging (Albany NY) 12, 2020.

124. Chen J, Foroozesh M and Qin Z: Transactivation of human endogenous retroviruses by tumor viruses and their functions in virus-associated malignancies. Oncogenesis 8: 6, 2019.

125. Gabaev I, Williamson JC, Crozier TWM, Schulz TF and Lehner PJ: Quantitative proteomics analysis of lytic KSHV infection in human endothelial cells reveals targets of viral immune modulation. Cell Rep 33: 108249, 2020

126. Wang-Johanning F, Li M, Esteva FJ, Hess KR, Yin B, Rycaj K, Plummer JB, Garza JG, Ambs S and Johanning GL: Human endogenous retrovirus type $\mathrm{K}$ antibodies and mRNA as serum biomarkers of early-stage breast cancer. Int J Cancer 134: $587-595,2014$

127. Tokuyama M, Kong Y, Song E, Jayewickreme T, Kang I and Iwasaki A: ERVmap analysis reveals genome-wide transcription of human endogenous retroviruses. Proc Natl Acad Sci USA 115: 12565-12572, 2018.

128. Mullins CS and Linnebacher M: Endogenous retrovirus sequences as a novel class of tumor-specific antigens: An example of HERV-H env encoding strong CTL epitopes. Cancer Immunol Immunother 61: 1093-1100, 2012.

129. Wang-Johanning F, Radvanyi L, Rycaj K, Plummer JB, Yan P, Sastry KJ, Piyathilake CJ, Hunt KK and Johanning GL: Human endogenous retrovirus $\mathrm{K}$ triggers an antigen-specific immune response in breast cancer patients. Cancer Res 68: 5869-5877, 2008. 
130. Kudo-Saito C, Yura M, Yamamoto R and Kawakami Y: Induction of immunoregulatory $\mathrm{CD} 271^{+}$cells by metastatic tumor cells that express human endogenous retrovirus $\mathrm{H}$. Cancer Res 74: 1361-1370, 2014.

131. Humer J, Waltenberger A, Grassauer A, Kurz M, Valencak J, Rapberger R, Hahn S, Löwer R, Wolff K, Bergmann M, et al: Identification of a melanoma marker derived from melanoma-associated endogenous retroviruses. Cancer Res 66 : 1658-1663, 2006.

132. Reis BS, Jungbluth AA, Frosina D, Holz M, Ritter E, Nakayama E, Ishida T, Obata Y, Carver B, Scher H, et al: Prostate cancer progression correlates with increased humoral immune response to a human endogenous retrovirus GAG protein. Clin Cancer Res 19: 6112-6125, 2013.

133. Chiappinelli KB, Strissel PL, Desrichard A, Li H, Henke C Akman B, Hein A, Rote NS, Cope LM, Snyder A, et al: Inhibiting DNA methylation causes an interferon response in cancer via dsRNA including endogenous retroviruses. Cell 162: 974-986, 2015.

134. Roulois D, Loo Yau H, Singhania R, Wang Y, Danesh A, Shen SY, Han H, Liang G, Jones PA, Pugh TJ, et al: DNA-demethylating agents target colorectal cancer cells by inducing viral mimicry by endogenous transcripts. Cell 162: 961-973, 2015.

135. Haffner MC, Taheri D, Luidy-Imada E, Palsgrove DN, Eich ML, Netto GJ, Matoso A, Nirschl TR, Zheng Q, Hicks JL, et al: Hypomethylation, endogenous retrovirus expression, and interferon signaling in testicular germ cell tumors. Proc Natl Acad Sci USA 115: E8580-E8582, 2018.

136. Argaw-Denboba A, Balestrieri E, Serafino A, Cipriani C, Bucci I, Sorrentino R, Sciamanna I, Gambacurta A, Sinibaldi-Vallebona P and Matteucci C: HERV-K activation is strictly required to sustain CD133+ melanoma cells with stemness features. J Exp Clin Cancer Res 36: 20, 2017.
137. Saini SK, Ørskov AD, Bjerregaard AM, Unnikrishnan A, Holmberg-Thydén S, Borch A, Jensen KV, Anande G, Bentzen AK, Marquard AM, et al: Human endogenous retroviruses form a reservoir of $\mathrm{T}$ cell targets in hematological cancers. Nat Commun 11: 5660, 2020.

138. Tatkiewicz W, Dickie J, Bedford F, Jones A, Atkin M, Kiernan M, Maze EA, Agit B, Farnham G, Kanapin A and Belshaw R: Characterising a human endogenous retrovirus(HERV)-derived tumour-associated antigen: Enriched RNA-Seq analysis of HERV-K(HML-2) in mantle cell lymphoma cell lines. Mob DNA 11: 9, 2020.

139. Ficial M, Jegede OA, Sant'Angelo M, Hou Y, Flaifel A, Pignon JC, Braun DA, Wind-Rotolo M, Sticco-Ivins M, Catalano PJ, et al: Expression of T-cell exhaustion molecules and human endogenous retroviruses as predictive biomarkers for response to nivolumab in metastatic clear cell renal cell carcinoma. Clin Cancer Res: 3084, 2020.

140. Siebenthall KT, Miller CP, Vierstra JD, Mathieu J, Tretiakova M, Reynolds A, Sandstrom R, Rynes E, Haugen E, Johnson A, et al: Integrated epigenomic profiling reveals endogenous retrovirus reactivation in renal cell carcinoma. EBioMedicine 41: 427-442, 2019. Attribution-NonCommercial-NoDerivatives 4.0 International (CC BY-NC-ND 4.0) License. 